\title{
CARACTERIZAÇÃO DA ZONA DE CONVERGÊNCIA DO ATLÂNTICO SUL EM CAMPOS ATMOSFÉRICOS RECENTES
}

\author{
SILVA, João Pedro Rodrigues - joao.9174@gmail.com \\ Universidade de São Paulo / USP \\ REBOITA, Michelle Simões - mireboita@gmail.com \\ Universidade Federal de Itajubá / UNIFEI
}

ESCOBAR, Gustavo Carlos Juan - gustavo.escobar44@gmail.com

Centro de Previsão do Tempo e Estudos Climáticos / CPTEC

\begin{abstract}
RESUMO: Como a Zona de Convergência do Atlântico Sul (ZCAS) é um dos principais sistemas meteorológicos causadores de chuva na região Sudeste do Brasil durante o verão, é de extrema importância conhecer suas características climatológicas, uma vez que essas podem ser utilizadas como indicadores de tal sistema em previsões de tempo. Portanto, o objetivo desse estudo é apresentar as diferenças da circulação atmosférica em eventos de ZCAS em relação à climatologia do verão usando a reanálise ERA-Interim num período recente (2006 a 2017). Além disso, o estudo apresenta uma análise dos eventos de ZCAS acoplados com sistemas de baixa pressão no oceano Atlântico Sul e identifica as fontes de umidade desses ciclones. O padrão atmosférico em episódios de ZCAS se distingue da climatologia do verão devido à circulação em altos níveis mostrar um cavado entre o Sul do Brasil e oceano Atlântico, que auxilia os movimentos ascendentes na região do ramo oceânico da ZCAS, e uma crista mais configurada sobre o Sudeste do país. Já com relação às variáveis associadas à umidade do ar, todas indicam um sinal de dipolo entre o Sudeste e o Sul do Brasil, isto é, em eventos de ZCAS predomina anomalias positivas no Sudeste e negativas no Sul. Cerca de $30 \%$ dos eventos de ZCAS ocorrem acoplados a um ciclone no oceano Atlântico Sul, fato que contribui para a manutenção da ZCAS. Esses ciclones têm como fonte de umidade a Amazônia e o setor tropical do oceano Atlântico Sul.
\end{abstract}

PALAVRAS-ChAVES: ZCAS. Variáveis Meteorológicas. Composições. Ciclones.

\section{CHARACTERIZATION OF THE SOUTH ATLANTIC CONVERGENCE ZONE IN RECENT ATMOSPHERIC FIELDS}

ABSTRACT: As the South Atlantic Convergence Zone (SACZ) is one of the main meteorological systems that produces rainfall in the southeast region of Brazil during the summer, it is important to know its climatological characteristics, once these can be used as SACZ indicators in weather forecast. Therefore, the objective of this study is to present the differences of the atmospheric circulation in events of SACZ in relation to the climatology of the summer using recent data (2006-2017) from the reanalysis ERAInterim. Besides, the study presents an analysis of the events of SACZ coupled with low pressure systems over the South Atlantic Ocean and it identifies the moisture sources of these cyclones. In episodes of SACZ the atmospheric pattern differs from the climatology of the summer due to the circulation at upper levels to show a trough between the south of Brazil and the Atlantic Ocean, which helps the ascending movements in the region of the oceanic branch of SACZ, and a ridge more configured on the southeast of Brazil. Regarding the variables associated with the air humidity, all indicate a dipole sign between the southeast and the south of Brazil, that is, in events of SACZ prevails positive anomalies in the southeast and negative one in the south. About $30 \%$ of SACZ events occur coupled to a cyclone in the South Atlantic Ocean, which contributes to the SACZ maintenance. The moisture sources of these cyclones are the Amazon and the tropical sector of the South Atlantic Ocean.

KEYWORDS: SACZ. Atmospheric Variables. Composites. Cyclones. 


\section{CARACTERIZACIÓN DE LA ZONA DE CONVERGENCIA DEL ATLÁNTICO SUR EN CAMPOS} ATMOSFÉRICOS RECIENTES

RESUMEN: Como la Zona de Convergencia del Atlántico Sur (ZCAS) es uno de los principales sistemas meteorológicos causantes de lluvia en la región Sudeste de Brasil durante el verano, es de extrema importancia conocer sus características climatológicas, ya que éstas pueden ser utilizadas como indicadores de tal sistema en pronósticos del tiempo. Por lo tanto, el objetivo de este estudio es presentar las diferencias de la circulación atmosférica en eventos de ZCAS en relación a la climatología del verano usando datos recientes del reanálisis ERA-Interim, en el período de 2006 a 2017. Además, el estudio presenta un análisis de los eventos de ZCAS acoplados con sistemas de baja presión en el océano Atlántico Sur e identifica las fuentes de humedad de estos ciclones. El patrón atmosférico en episodios de ZCAS se distingue de la climatología del verano debido a que la circulación en altura muestra una vaguada entre el Sur de Brasil y el océano Atlántico que ayuda a los movimientos ascendentes en la rama oceánica de la ZCAS y una cuña más configurada sobre el sureste del país. En cuanto a las variables asociadas con la humedad del aire, todas indican una señal de dipolo entre el Sureste y el Sur de Brasil, es decir, en eventos de ZCAS predomina anomalías positivas en el Sureste y negativas en el Sur. Cerca del 30\% de los eventos de ZCAS ocurren acoplados a un ciclón en el océano Atlántico Sur, hecho que contribuye al mantenimiento de la ZCAS. Estos ciclones tienen como fuente de humedad la Amazonia y el sector tropical del océano Atlántico Sur.

PALABRAS CLAVE: ZCAS. Variables Meteorológicas. Composiciones. Ciclones.

\section{INTRODUÇÃO}

As regiões Centro-Oeste e Sudeste do Brasil apresentam um período seco entre abril a setembro e outro chuvoso de outubro a março (REBOITA et al., 2010). Portanto, essas regiões são caracterizadas por um clima de monção. Segundo Ramage (1971), a monção é um fenômeno atmosférico que se desenvolve sobre regiões continentais em resposta ao aquecimento diferencial entre o oceano e o continente ao longo do ano. Esse aquecimento diferencial favorece a reversão sazonal do sentido dos ventos em baixos níveis da atmosfera, de forma que na estação quente, o ar úmido é transportado do oceano para o continente favorecendo a ocorrência de precipitação. De acordo com Marengo et al. (2012) e Reboita et al. (2010), na América do Sul (AS) a monção é chamada de Monção Sul-Americana (MSA) e não mostra claramente a reversão sazonal do sentido dos ventos, isso só é constatado quando a média anual das componentes do vento é subtraída da média mensal. Portanto, o que ocorre na MSA é uma reversão das anomalias do sentido dos ventos em baixos níveis (ZHOU e LAU, 1998). O período úmido da MSA inicia-se em meados da primavera sobre a Amazônia equatorial, quando os ventos alísios de nordeste começam a se intensificar e acabam transportando mais umidade para a região Norte do Brasil que nas demais épocas do ano (DURAN-QUESADA et al., 2012; MARENGO et al, 2001).

A umidade que é transportada do oceano Atlântico Tropical para a região Norte do Brasil, em conjunto com a evapotranspiração da floresta Amazônica, além de contribuir para a precipitação em tal região, é em parte transportada para o Sul e Sudeste do Brasil pelos ventos a leste da Cordilheira dos Andes, conhecidos como Jatos de Baixos Níveis (JBN; SANTOS e REBOITA, 2019). Na região Sudeste, além da umidade proveniente da Amazônia, outra fonte de umidade é o oceano Atlântico Sul, uma vez que durante a estação chuvosa o Anticiclone Subtropical do Atlântico Sul (ASAS) encontra-se na sua posição mais a leste (REBOITA et al., 2018) propiciando o transporte de ar úmido do oceano 
para o continente (DRUMOND et al., 2008; REBOITA et al., 2018). Quadro et al. (2012) ressalta a importância do ASAS no clima do Brasil, ao mencionar que somente o transporte de umidade da região Amazônica não seria suficiente para compor toda a umidade observada no Sul e Sudeste do Brasil no verão.

Durante o período úmido da MSA, a junção dos sistemas mencionados com a convecção típica do período quente (a convecção corresponde ao transporte vertical do ar devido ao intenso aquecimento da superfície) contribui para a formação da Zona de Convergência do Atlântico Sul (ZCAS), que é caracterizada por uma banda persistente de nebulosidade e precipitação orientada no sentido noroeste-sudeste desde o Sul/Sudeste da região Amazônica até o Sudoeste do oceano Atlântico Sul (KOUSKY, 1988; CARVALHO et al., 2004). A ZCAS é responsável por sequências de dias chuvosos que muitas vezes acabam causando eventos extremos de precipitação e, por consequência, inundações e deslizamentos de terra (SELUCHI e CHOU, 2009; REBOITA et al., 2017). A circulação atmosférica de verão na AS também mostra um anticiclone em altos níveis conhecido como Alta da Bolívia, que de acordo com Lenters e Cook (1997), tem sua formação associada principalmente à liberação de calor latente na Amazônia. Já, corrente abaixo da Alta da Bolívia, há um cavado entre o Nordeste do Brasil e o oceano Atlântico. Muitas vezes podem aparecer vórtices fechados no interior do cavado que recebem o nome de Vórtices Ciclônicos de Altos Níveis (VCANs, KOUSKY e GAN, 1981; REBOITA et al., 2017).

Nogués Peagle et al. (2002) destacam que a ZCAS está diretamente relacionada com a MSA, portanto os episódios de ZCAS começam a se desenvolver no início da primavera austral e a predominar durante todo o verão austral. Ainda na escala intrasazonal, Nogués-Paegle e Mo (1997) sugerem que - JBN desempenha papel essencial na intensidade e localização da ZCAS e propicia uma gangorra de precipitação, que ocorre entre o Sudeste do Brasil e o Sudeste da América do Sul (Rio Grande do Sul, Paraguai, Norte da Argentina e Uruguai). Quando o JBN se dirige para o Sudeste do Brasil há intensificação da ZCAS com o consequente aumento de precipitação nessa região; quando se dirige para o Sudeste da América do Sul, há enfraquecimento e redução da precipitação no Sudeste do Brasil. Esse padrão é chamado de gangorra, pois quando há anomalias positivas de precipitação num setor, há redução em outro.

Nem todos os episódios de ZCAS apresentam a mesma configuração. Nesse sentido, Escobar e Costa (2005) realizaram uma classificação sinótica dos eventos de ZCAS, no período de 1980 a 2000, através da técnica de Análise de Componentes Principais. Foram obtidos 3 padrões sinóticos principais associados à ZCAS: 1) formação de uma onda frontal no oceano Atlântico, nas latitudes do norte da região Sul do Brasil, sendo que ao sul do ciclone aparece configurado um anticiclone que permanece quase estacionário durante o início do evento; 2) passagem de uma frente fria com trajetória zonal que se acopla a uma outra frente fria que já estava atuando sobre o oceano Atlântico próximo ao Sudeste brasileiro e 3) avanço de uma frente fria clássica desde o sul do continente. Escobar (2018) também realizou uma análise da classificação sinótica de eventos de ZCAS usando dados recentes (2006 a 2017). Nesse estudo também foram identificados três padrões sinóticos de ZCAS. O padrão sinótico de ZCAS mais frequente relacionou-se com uma frente estacionária no oceano na altura do Sudeste do Brasil e com a presença do ASAS mais intenso localizado ao sul da sua posição climatológica, adquirindo características de tipo bloqueio. Em certas ocasiões este padrão sinótico está relacionado com a presença de ciclones 
no oceano com pouca baroclinia. O segundo padrão sinótico esteve associado com uma frente fria clássica sobre o Sudeste e Centro-Oeste do Brasil, apresentando uma intensa convergência de umidade sobre o interior do continente. Por último, o terceiro padrão sinótico relacionou-se com uma intensa e abrangente área de baixa pressão sobre o oceano com características barotrópicas, favorecendo a forte advecção de ar quente e úmido desde a região amazônica. Tanto em Escobar e Costa (2005) e Escobar (2018), o padrão sinótico mais frequente da ocorrência de ZCAS indica que o ramo oceânico desse sistema se acopla a um ciclone. Embora a literatura não aborde expressamente a relação da ZCAS com os ciclones oceânicos, estudos recentes têm indicado a associação da umidade proveniente do continente com os ciclones formados na costa sudeste do Brasil, principalmente em eventos de ciclones subtropicais (GOZZO et al., 2017; REBOITA et al., 2018).

Diante da contextualização prévia, o presente estudo tem como objetivo descrever as características típicas dos campos meteorológicos associados a eventos de ZCAS (climatologia sinótica) em comparação à climatologia da estação do verão (dezembro a fevereiro), no período de 2006 a 2017. Além disso, é avaliada a climatologia sinótica dos eventos de ZCAS que tiveram o ramo oceânico acoplado a um ciclone, bem como identificadas as fontes de umidade relacionadas a esses ciclones. Os padrões que serão descritos contribuirão para identificação de episódios de ZCAS em saídas de modelos de previsão de tempo, auxiliando os meteorologistas do ramo operacional.

\section{METODOLOGIA}

\subsection{IDENTIFICAÇÃO DA ZONA DE CONVERGÊNCIA DO ATLÂNTICO SUL}

O Grupo de Previsão de Tempo (GPT) do Centro de Previsão de Tempo e Estudos Climáticos (CPTEC) do Instituto Nacional de Pesquisas Espaciais (INPE) desde 2006 elabora cartas sinóticas de superfície e de outros 4 níveis atmosféricos (850, 700, 500 e $250 \mathrm{hPa}$ ). Recentemente, essas cartas foram reanalisadas para a identificação de episódios de ZCAS a fim de fornecer informações ao projeto "Caracterização da circulação atmosférica associada com episódios de Zona de Convergência do Atlântico Sul (ZCAS) e sua relação com eventos extremos de chuva na região Sudeste do Brasil" ao qual esse estudo faz parte.

Os eventos de ZCAS foram identificados no período de outubro de 2006 a dezembro de 2017 seguindo a metodologia de Escobar e Matoso (2018) em que as características a seguir devem aparecer concomitantemente nas cartas sinóticas.

1) presença do Jato Subtropical (JS) contornando um cavado e dando suporte ao sistema que atua na superfície (cavado ou frente subtropical);

2) o ramo norte do Jato Polar (JPN) pode aparecer em algumas ocasiões acoplado ao JS nos casos em que aparece a presença de uma frente fria (clássica) no oceano;

3) existência de gradiente horizontal de temperatura potencial equivalente em $850 \mathrm{hPa}$ se estendendo desde o oceano até o interior do continente; 
4) o fluxo de umidade em $850 \mathrm{hPa}$ é bem estabelecido desde a região Amazônica até o oceano Atlântico passando pela região Centro-Oeste e Sudeste do país;

5) o campo de velocidade vertical (ômega) ascendente (valores negativos) em $500 \mathrm{hPa}$ aparece em fase com o escoamento convergente em $850 \mathrm{hPa}$;

6) a $A B$ e o cavado do Nordeste, geralmente, aparecem bem definidos nos casos de ZCAS e

7) a zona de convergência em baixos níveis e a presença de nebulosidade devem persistir por pelo menos 3 dias consecutivos.

A aplicação da metodologia descrita permitiu registrar a data de início e fim de cada evento de ZCAS. Com isso, foi elaborada uma climatologia da frequência e da duração dos eventos de ZCAS por mês do ano. Quando um evento de ZCAS ocorreu no final de um mês e perdurou até o mês seguinte, o evento foi considerado como pertencente ao mês em que teve início, isso segue a metodologia também usada no GPT do CPTEC/INPE. Ressalta-se que, embora o período de estudo seja inferior a 30 anos, a média do período de 2006 a 2017 será chamada de climatologia para facilitar a redação e exposição dos resultados.

\subsection{CLIMATOLOGIA SINÓTICA}

Quando são determinadas as médias de variáveis atmosféricas associadas à ocorrência de um determinado sistema atmosférico de escala sinótica, chama-se o estudo de climatologia sinótica. Entretanto, as médias também podem ser denominadas de composições. Aqui são determinadas composições apenas para os eventos de ZCAS ocorridos durante o verão (dezembro a fevereiro) do período de 2006 a 2017. A fim de destacar as características dos campos atmosféricos em eventos de ZCAS em relação à climatologia do verão, essa também foi calculada. Por fim, computaram-se as anomalias que correspondem à composição dos casos de ZCAS menos a média climatológica do período de verão.

Nessa etapa do estudo utilizaram-se dados obtidos da reanálise ERAInterim, que é oriunda de observações meteorológicas assimiladas pelo modelo global do European Centre for Médium-Range Weather Forecast (ECMWF). A reanálise ERA-Interim possui resolução espacial de $0,75^{\circ}$ de latitude por $0,75^{\circ}$ de longitude e frequência de 6 horas (DEE et al., 2011). As composições foram geradas utilizando-se apenas o horário das $00 \mathrm{Z}$. A tabela 1 descreve as variáveis e os respectivos níveis de pressão utilizados no estudo. 
Tabela 1 - Variáveis atmosféricas da ERA-Interim utilizadas no estudo e os respectivos níveis de pressão. Também são apresentadas as variáveis secundárias (obtidas a partir das variáveis fornecidas pela ERA-Interim).

Variável (unidade)

Altura Geopotencial (m)

Divergência (1/s)

Variável Secundária

Velocidade Vertical ou ômega ( $\mathrm{Pa} / \mathrm{s})$

Pressão ao nível médio do mar ( $\mathrm{hPa}$ )

Umidade Específica $(\mathrm{kg} / \mathrm{kg})$

Componentes horizontais do vento: u e v $(\mathrm{m} / \mathrm{s})$
250

Níveis de Pressão (hPa)

$300 \quad 500 \quad 850$

1000

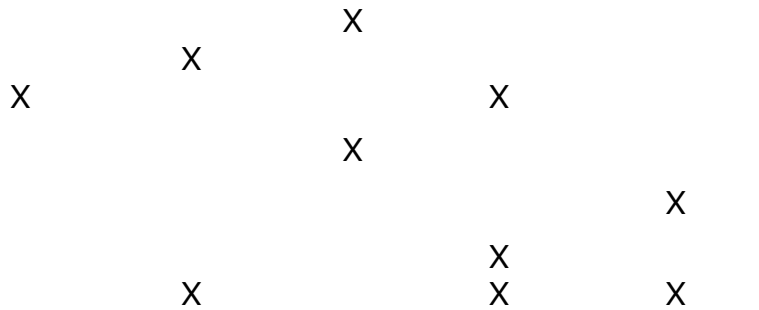

Também foram utilizados dados diários de precipitação do Global Precipitation Climatology Project (GPCP; ADLER et al., 2003), com resolução espacial de $1^{\circ}$.

Na seção resultados são apresentados os campos de:

- Pressão ao nível médio do mar e vetores do vento a 10 metros de altura, que mostram as regiões de alta e baixa pressão e a circulação atmosférica.

- Umidade específica e vetores de vento em $850 \mathrm{hPa}$ a fim de mostrar as regiões de convergência do vento e indicação do transporte de umidade, para a formação da ZCAS.

- Divergência do fluxo de umidade integrado na vertical e vetores do fluxo de umidade, utilizando nove níveis verticais de $1000 \mathrm{hPa}$ a $200 \mathrm{hPa}$, para destacar o transporte de umidade e sua divergência e convergência.

- Precipitação e vetores de vento em 850 hPa para apresentar a chuva associada à ZCAS.

- Velocidade vertical (ômega) e altura geopotencial em 500 hPa para a localização das regiões de movimento ascendente e subsidente.

- Divergência de massa e linhas de corrente em 300 hPa para verificar as regiões de cavados e cristas em altos níveis e as regiões de divergência em altos níveis que dão suporte à convergência em baixos níveis.

\subsection{ANÁLISE DE CICLONES ASSOCIADOS À ZCAS}

Em alguns eventos de ZCAS, seu ramo oceânico aparece associado com um ciclone no oceano Atlântico Sul (ESCOBAR e COSTA, 2005; ESCOBAR, 2018). Portanto, também constituiu objetivo do estudo selecionar os casos de ZCAS acoplados com sistemas de baixa pressão, a fim de identificar possíveis diferenças em relação à composição com todos os eventos, bem como as fontes de umidade associadas aos ciclones. Após a seleção dos casos de ZCAS associados a ciclones, determinaram-se composições considerando um dia antes da gênese do ciclone, o dia da sua formação e um dia posterior ao aparecimento do ciclone. Essas três composições foram comparadas com a composição considerando todos os eventos de ZCAS. Os campos analisados aqui são: 
pressão ao nível médio do mar e vetores do vento a 10 metros de altura, divergência de massa e linhas de corrente em 300 hPa, divergência do fluxo de umidade integrado na vertical, umidade específica e vetores do vento no nível de 850 hPa e precipitação e vetores do vento no nível 850 hPa.

Para identificação das fontes de umidade associadas aos ciclones utilizouse o modelo HYSPLIT (STEIN et al., 2015), na sua opção isobárica e backward, isto é, uma vez identificado a posição central de um ciclone, o modelo identifica as trajetórias das parcelas de ar que chegam até ele. O HYSPLIT é um modelo utilizado para computar trajetórias simples de parcelas de ar, além de realizar simulações de transporte de massas de ar, dispersão de poluentes, transformação química, deposição de partículas etc. Investigou-se o transporte de umidade em 18 casos de ciclones que estiveram associados com eventos de ZCAS, porém na análise do HYSPLIT, por motivos de brevidade, serão mostrados somente três casos: 22 de janeiro de 2007; 20 de janeiro de 2008 e 10 de dezembro de 2011.

\section{RESULTADOS}

\subsection{CLIMATOLOGIA DA ZCAS}

No período de 2006 a 2017, foram registrados 114 casos de ZCAS (Tabela 2), sendo dezembro o mês com maior ocorrência e abril o de menor frequência desse sistema (Figura 1). Já Ambrizzi e Ferraz (2005) num estudo com 48 eventos de ZCAS também indicaram dezembro como o mês de maior ocorrência desse sistema. A metodologia desses autores diverge em alguns aspectos da utilizada no presente estudo, por exemplo, um episódio de ZCAS que inicia em um dado mês e acaba em outro será registrado no mês em que apresentar maior duração.

Os eventos de ZCAS possuem duração média de 5 dias (Tabela 3); entre os eventos estudados, o com maior duração se iniciou no dia 23 de dezembro de 2013 e perdurou por 15 dias.

Tabela 2 - Número de eventos de ZCAS entre outubro a abril de 2006 e 2017 identificados com a metodologia de Escobar e Matoso (2018) aplicada às cartas sinóticas do GPT.

\begin{tabular}{ccccccccccccccccc}
\hline Meses & 2006 & 2007 & 2008 & 2009 & 2010 & 2011 & 2012 & 2013 & 2014 & 2015 & 2016 & 2017 & $\begin{array}{c}\text { Total } \\
\text { mensal }\end{array}$ \\
\hline Out & 1 & 1 & 1 & 2 & 2 & 2 & - & 1 & 1 & 1 & 1 & - & 13 & 1,3 \\
Nov & 2 & 2 & 2 & - & 1 & 2 & 3 & 1 & 2 & - & 1 & 2 & 18 & 1,8 \\
Dez & 2 & 2 & 3 & 2 & 3 & 3 & 1 & 1 & 2 & - & 2 & 3 & 24 & 2,2 \\
Jan & - & 2 & 3 & 3 & 1 & 1 & 3 & 2 & 1 & 1 & 2 & 3 & 22 & 2 \\
Fev & - & 1 & 2 & 1 & - & 2 & 1 & 2 & 2 & 3 & 1 & 2 & 17 & 1,7 \\
Mar & - & 1 & 1 & 2 & 2 & - & 2 & 1 & 2 & 3 & 2 & 1 & 17 & 1,7 \\
Abr & - & - & - & 1 & - & 1 & - & - & - & 1 & - & - & 3 & 1 \\
\hline Total & 5 & 9 & 12 & 11 & 9 & 11 & 10 & 8 & 10 & 9 & 9 & 11 & 114 & \\
\hline
\end{tabular}


Tabela 3 - Tempo de vida médio da ZCAS entre 2006 e 2017

\begin{tabular}{ccc}
\hline $\begin{array}{c}\text { Meses do } \\
\text { ano }\end{array}$ & $\begin{array}{c}\text { Tempo de vida médio } \\
\text { (horas) }\end{array}$ & $\begin{array}{c}\text { Tempo de vida médio } \\
\text { (dias) }\end{array}$ \\
\hline Outubro & 91,2 & 3,8 \\
Novembro & 129,6 & 5,4 \\
Dezembro & 129,6 & 5,4 \\
Janeiro & 127,2 & 5,3 \\
Fevereiro & 129,6 & 5,4 \\
Março & 124,8 & 5,2 \\
Abril & 86,4 & 3,6 \\
\hline
\end{tabular}

\section{PORCENTAGEM DE EVENTOS ZCAS (2006 - 2017)}

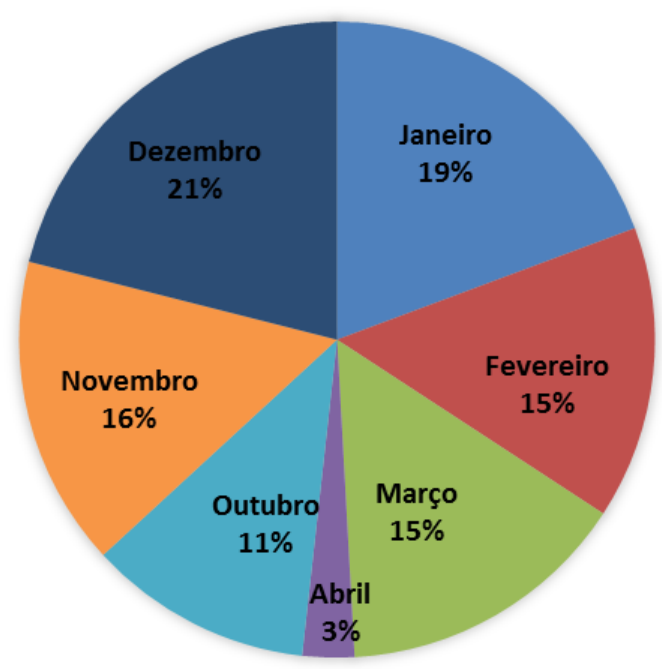

Figura 1 - Frequência percentual de eventos de ZCAS entre outubro a abril de 2006 a 2017.

\subsection{CLIMATOLOGIA SINÓTICA}

Com o objetivo de apresentar a "assinatura" da ZCAS nos campos atmosféricos bem como suas diferenças em relação à climatologia, determinaram-se composições com as variáveis descritas na seção 2 considerando 63 eventos de ZCAS, que é o total identificado no período de verão (Tabela 2). Já a climatologia incluiu todos os dias no período do verão entre 2006 a 2017. Para as composições dos eventos de ZCAS, as médias foram realizadas considerando todos os dias de duração dos eventos (e não apenas o primeiro dia). Dessa forma, o número de dias envolvidos é bem superior a 63 . Tanto nas composições dos eventos de ZCAS quanto na climatologia foram utilizados dados do horário sinótico das $00 \mathrm{Z}$. 
A Figura 2 destaca na coluna da esquerda as composições dos eventos de ZCAS, na coluna do meio a climatologia do verão e na coluna da direita as anomalias (composições menos climatologia) para as variáveis pressão a nível médio do mar e vetores do vento a 10 metros de altura, umidade específica e vetores do vento no nível de $850 \mathrm{hPa}$ e divergência do fluxo de umidade integrado na vertical. Em eventos de ZCAS, a característica mais marcante nas composições da pressão ao nível médio do mar e vento a 10 metros de altura (Figura 2a) é a presença de uma região com menor pressão do que a vizinhança entre a costa Sul-Sudeste do Brasil e o oceano Atlântico, onde predominam ventos com giro ciclônico. Na climatologia, esse padrão é mais suave (Figura 2b). Já no campo das anomalias (Figura 2c) é ressaltado o menor valor de pressão entre o continente e o oceano em relação à climatologia. Essa região indica a localização do ramo oceânico da ZCAS. Sobre o continente praticamente não há diferenças entre a composição da pressão e a climatologia. No campo da umidade específica em $850 \mathrm{hPa}$, tanto a composição quanto as anomalias indicam maior umidade da Amazônia ao oceano Atlântico Sul, no sentido noroeste-sudeste, em eventos de ZCAS (Figura 2d, f). No interior do continente a umidade é transportada da região Norte para a Sudeste pelo JBN, que tem sua posição destacada pelo contorno em vermelho nas Figuras $3 d$ e $3 e$, e na região mais costeira, o transporte de umidade do oceano para o continente ocorre através dos ventos do setor oeste do ASAS. Sobre os Estados de Mato Grosso, Goiás e sul de Minas Gerais, nota-se que o JBN em eventos de ZCAS possui ventos com componente zonal mais intensa do que na climatologia. Isso indica maior organização do transporte de umidade em sentido à região Sudeste do Brasil. Além disso, o encontro do JBN com os ventos promovidos pelo ASAS é importante para a configuração da ZCAS sobre o Sudeste do país. Os resultados descritos concordam com Herdies et al. (2002), que indicaram que o transporte de umidade dos trópicos para os extratrópicos da AS é mais eficiente durante a ocorrência de ZCAS do que durante a sua ausência. Outro fato interessante na Figura $2 \mathrm{f}$ é o dipolo entre as anomalias de umidade específica, também denominado de padrão gangorra, entre o Sudeste do Brasil, com predomínio de anomalias positivas, e o Sul, com anomalias negativas; o que concorda com Nogués-Paegle e Mo (1997). Enquanto no Sudeste as anomalias do vento indicam ventos mais intensos do continente para o oceano em eventos de ZCAS, no Sul os ventos são mais fracos.

A fim de apresentar uma análise mais robusta do campo de umidade, foi determinado o fluxo de umidade integrado na vertical, apresentado em vetores (Figura $2 \mathrm{~g}, \mathrm{~h}, \mathrm{i}$ ) e a divergência desse fluxo. Com relação à divergência, essa é representada por valores positivos, enquanto à convergência do fluxo de umidade é representada por valores negativos (Figura $2 \mathrm{~g}, \mathrm{~h}, \mathrm{i}$ ). Em eventos de ZCAS, a convergência do fluxo de umidade é mais intensa sobre o São Paulo e Minas Gerais bem como no oceano adjacente. Essa característica é bem evidente no campo das anomalias (Figura $2 \mathrm{i}$ ) e se assemelha àquela do campo da umidade específica em $850 \mathrm{hPa}$ (Figura 2f). Outro campo com padrão similar a esses é o da precipitação (Figura $3 a, b, c)$ em que as anomalias refletem bem o padrão gangorra entre o Sul e Sudeste do Brasil. Em geral, os campos mostrados até aqui indicam que a maior diferença entre os eventos de ZCAS e a climatologia do verão ocorre entre o Sudeste do Brasil e o oceano Atlântico e não desde a Amazônia ao Atlântico. Uma sugestão para isso é que a atividade convectiva na Amazônia e parte do Centro-Oeste do Brasil é típica do período quente e não dependente da existência da ZCAS (pois independente da 
configuração de outros sistemas como JBN, há conveç̧ão e também o transporte de umidade pelos ventos alísios na Amazônia). Além disso, deve-se ressaltar o padrão anômalo oposto das variáveis atmosféricas no Sul do Brasil ao da região da ZCAS, quando há predomínio desse fenômeno.

Um proxy da convecção é a presença de movimentos verticais ascendentes na atmosfera. A segunda linha da Figura 3 mostra essa variável em $500 \mathrm{hPa}$. Os movimentos ascendentes são mais intensos do sul da Amazônia, passando pelo Sudeste do Brasil, ao oceano Atlântico em eventos de ZCAS do que na climatologia. Sobre o interior do continente, esses movimentos são favorecidos pelo intenso aquecimento radiativo da superfície durante o verão, já entre o Sudeste do Brasil e o oceano, possuem o aporte de um cavado em níveis médios e altos da atmosfera (Figuras 3d). De acordo com Kousky e Elias (1982) e com a teoria de Sutcliffe (1947), a leste dos cavados predomina advecção de vorticidade absoluta ciclônica, que é proporcional à divergência de massa. Logo, se há divergência há remoção de massa da coluna atmosférica e para ocorrer compensação, ocorrem movimentos ascendentes. De fato, a Figura $3 \mathrm{~g}$ mostra divergência a leste do cavado em $300 \mathrm{hPa}$ em eventos de ZCAS. 
a)

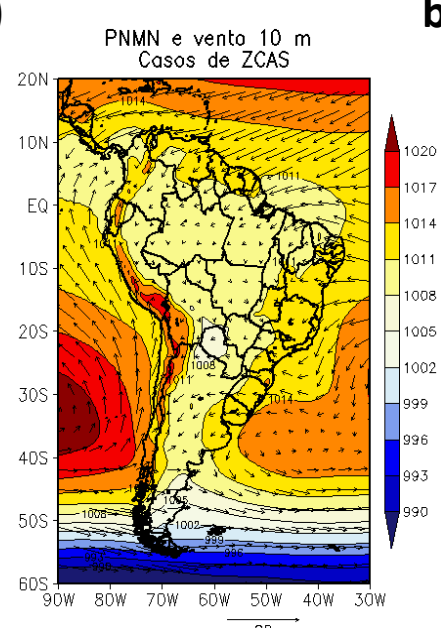

d)

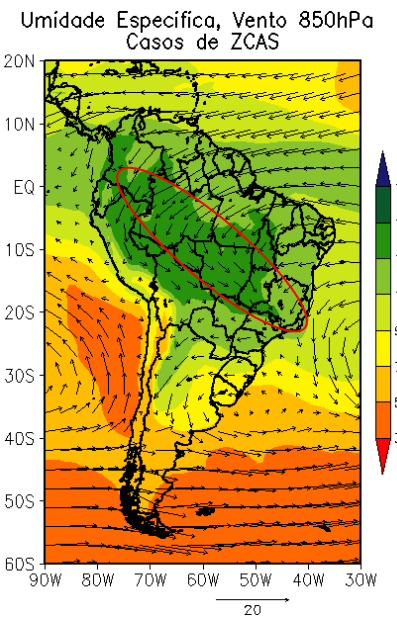

g)

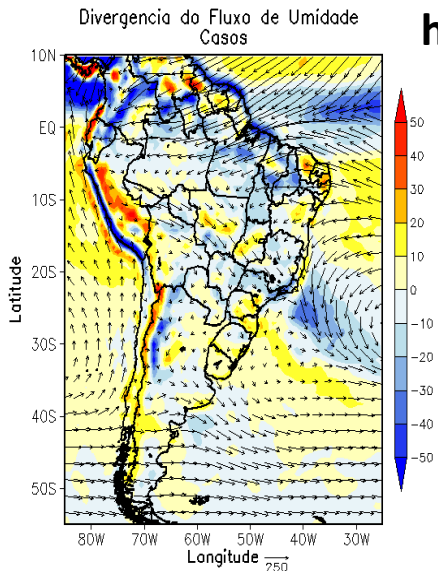

b)

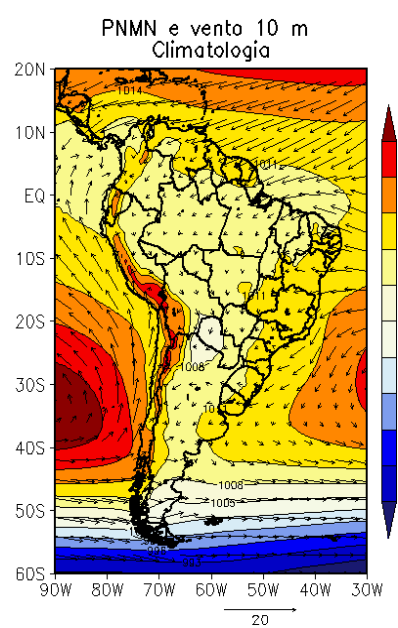

e)

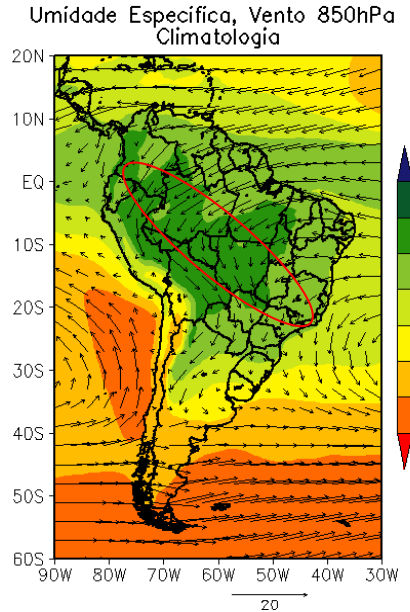

h)

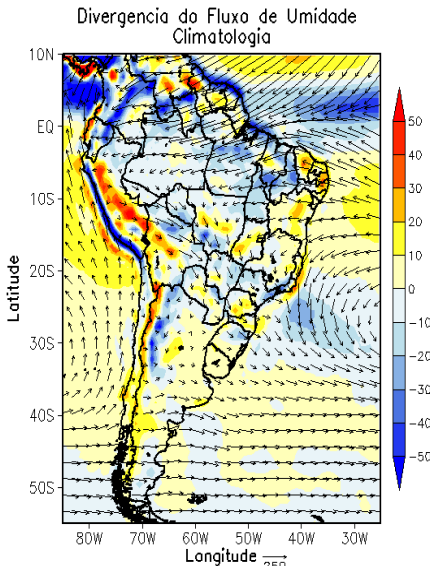

c)

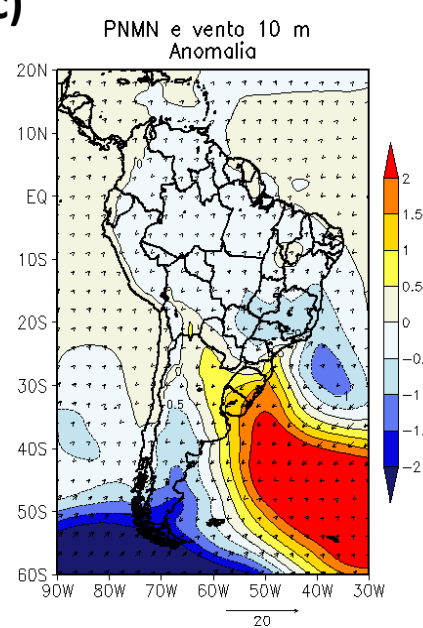

f)

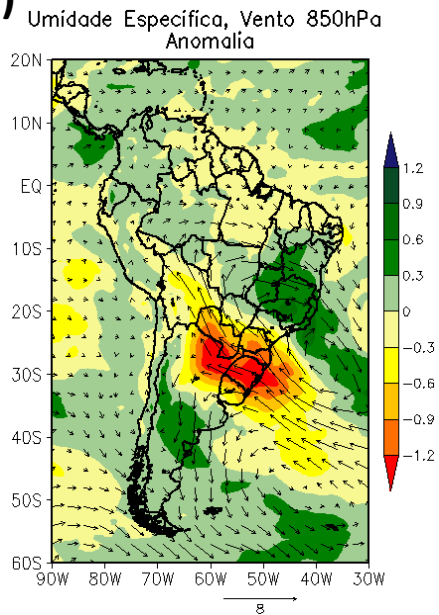

i)

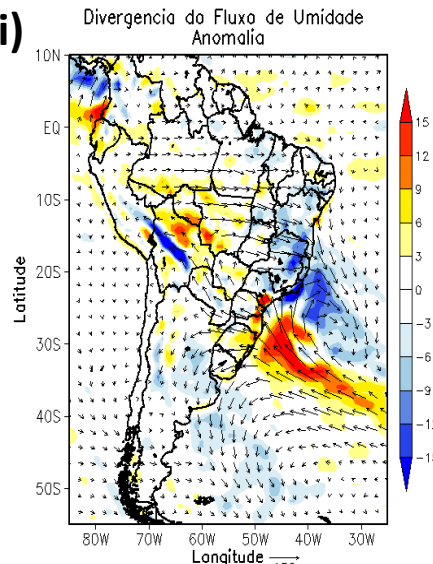

Figura 2 - Campos de pressão ao nível médio do mar (hPa) e vetores do vento a 10 metros de altura $\left(\mathrm{m} \mathrm{s}^{-1}\right)$, umidade específica $\left(\mathrm{g} \mathrm{kg}^{-1}\right)$ e vetores do vento $\left(\mathrm{m} \mathrm{s}^{-1}\right)$ no nível de $850 \mathrm{hPa}$ e divergência do fluxo de umidade integrado na vertical $\left(\mathrm{kg} \mathrm{m}^{-1} \mathrm{~s}^{-1}\right)$, onde (a), (d) e (g) são as composições dos dias de ocorrência de ZCAS no período de dezembro a fevereiro entre 2006 a 2017; (b), (e) e (h) são as médias climatológicas de 2006 a 2017 no período de dezembro a fevereiro; (c), (f) e (i) são as diferenças entre a 
composição dos casos de ZCAS e a média climatológica (anomalia) no período de dezembro a fevereiro entre 2006 a 2017.

Considerando a climatologia da circulação atmosférica em $300 \mathrm{hPa}$, há a presença da $A B$, uma crista entre o Sudeste do Brasil e oceano Atlântico e do cavado nas cercanias do Nordeste do Brasil. Essas configurações ocorrem na climatologia independentemente da existência de ZCAS, uma vez que estão associadas à intensa atividade convectiva na Amazônia (LENTERS E COOK, 1997). Entretanto, durante os eventos de ZCAS algumas diferenças ocorrem em termos da circulação (Figura $3 \mathrm{~g}$ ), isto é, há um cavado sobre o Sul do Brasil (que vai favorecer os movimentos ascendentes sobre o oceano), uma crista mais configurada sobre o Sudeste do país (que se deve ao fato do aquecimento da coluna atmosférica pela liberação de calor latente de condensação associado à precipitação em tal região) e o cavado nas cercanias do Nordeste. 
a) Precipitocoo e Vento $850 \mathrm{hPo}$

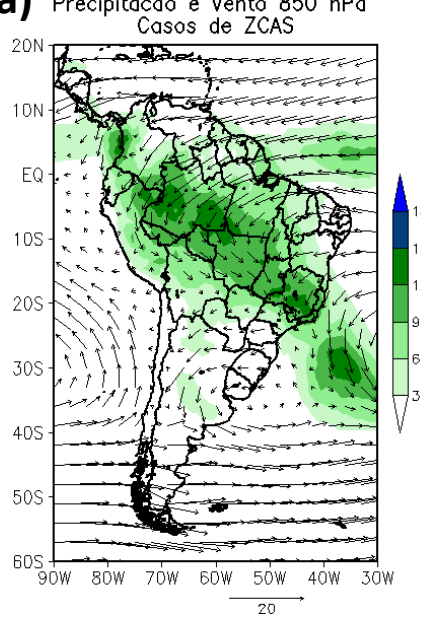

d)

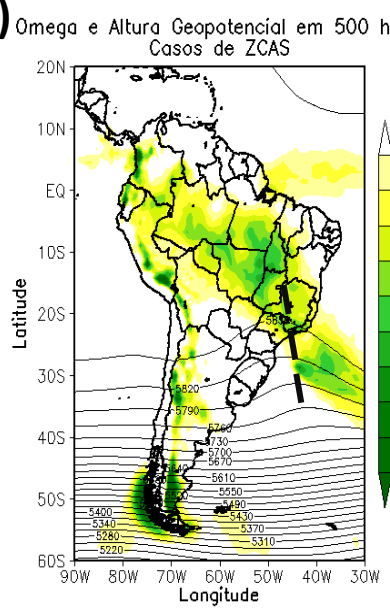

g)

Divergencio e Linhas de Corrente $(300 \mathrm{hPa})$

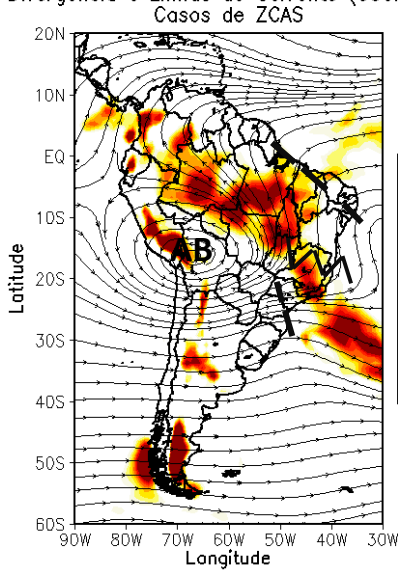

b)

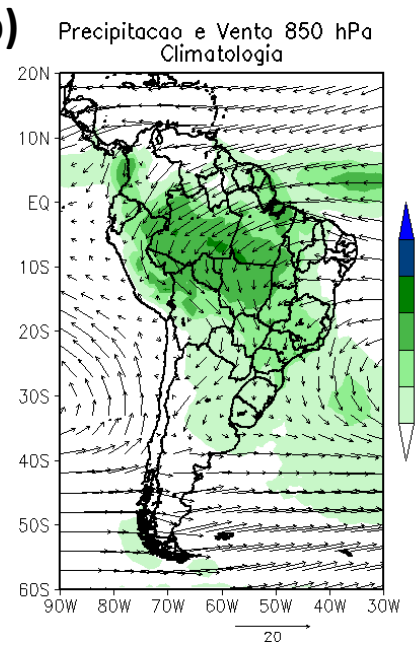

e)

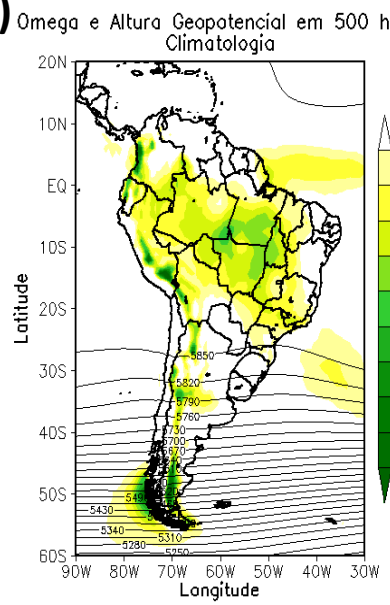

h)

Divergencio e Linhas de Corrente $(300 \mathrm{hPo})$

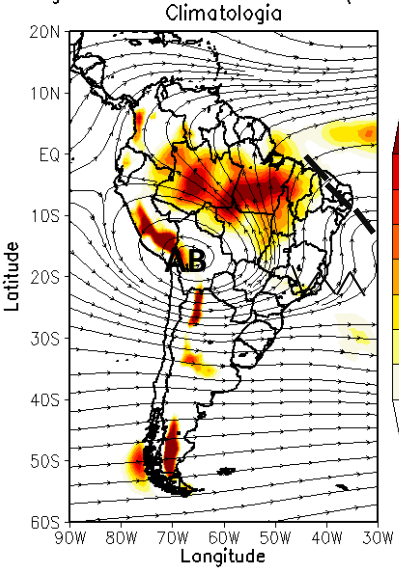

c)

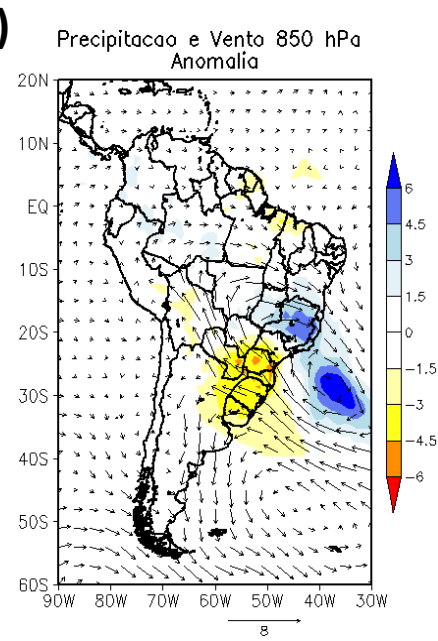

f) Bmego e Altura Geopotencial em $250 \mathrm{hPo}$

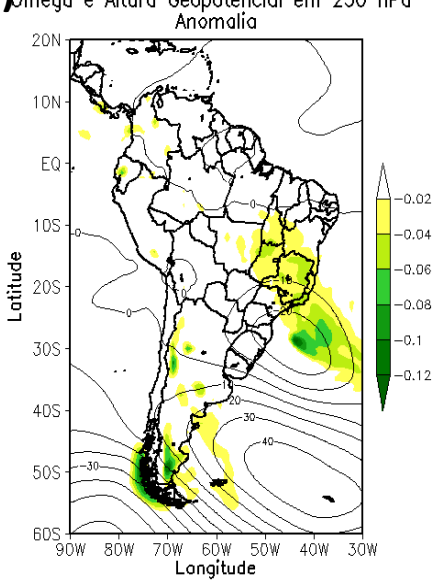

i)

Divergencio e Linhas de Corrente (300hPo)

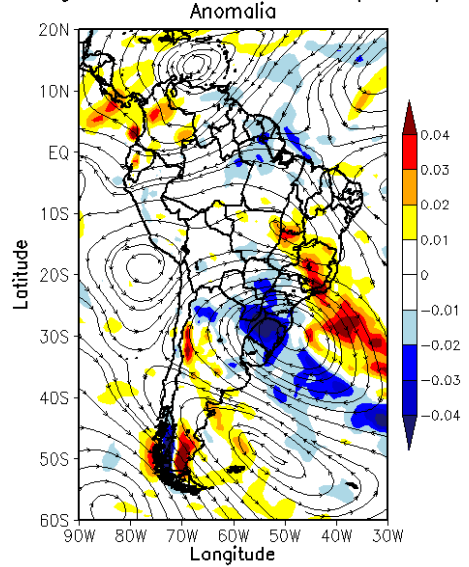

Figura 3 - Campo de precipitação $\left(\mathrm{mm} \mathrm{dia}^{-1}\right)$ e vetores do vento $\left(\mathrm{m} \mathrm{s}^{-1}\right)$ no nível de 850 $\mathrm{hPa}$, divergência de massa $\left(1 \mathrm{~s}^{-1}\right)$ e linhas de corrente $\left(\mathrm{m} \mathrm{s}^{-1}\right)$ no nível de $300 \mathrm{hPa}$, ômega (Pa s-1) e altura geopotencial (gpm) no nível de $500 \mathrm{hPa}$, onde: (a), (d) e (g) são as composição dos dias de ocorrência de ZCAS no período de dezembro a fevereiro entre 2006 a 2017; (b), (e) e (h) são as médias climatológicas de 2006 a 2017 no período de dezembro a fevereiro; (c), (f) e (i) são as diferenças entre a composição dos casos de 
ZCAS e a média climatológica (anomalia) no período de dezembro a fevereiro entre 2006 a 2017.

\subsection{ANÁLISE DE CICLONES ASSOCIADOS À ZCAS}

Foram selecionados 18 eventos de ZCAS que estiveram associados com ciclones no período de 2006 a 2017. Isso representa cerca de 30\% dos casos de ZCAS registrados no período em estudo. Aqui são apresentadas as composições de um dia antes da formação dos ciclones a um dia após à gênese, bem como a diferença desses campos em relação à composição dos eventos de ZCAS.

Um dia antes da formação dos ciclones tem-se um cavado invertido na costa do sudeste do Brasil (Figura 4a). Desde esse dia, a região de menor pressão aparece cercada a sul e a oeste pelo ASAS (Figura 4 a-c). Como discutido por Campetella e Vera (2002), os sistemas de baixa pressão induzem o escoamento do JBN para a região deles de forma que o calor e umidade transportados pelo jato favorecem os ciclones. Por outro lado, o ciclone ajuda o JBN a se intensificar. Assim, há um mecanismo de retroalimentação. Esse ambiente por sua vez é propício à manutenção da ZCAS, já que está ocorrendo suprimento de umidade. Outro fato que contribui para a manutenção da ZCAS é o lento deslocamento do ciclone, uma vez que tem seu deslocamento dificultado pela presença do ASAS. Isso é bem evidente no campo das anomalias (Figura 4 $d-f)$.

a)

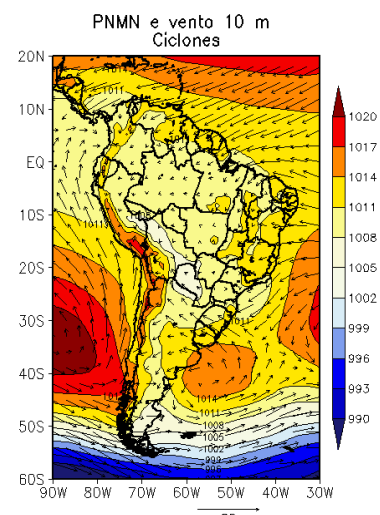

d)

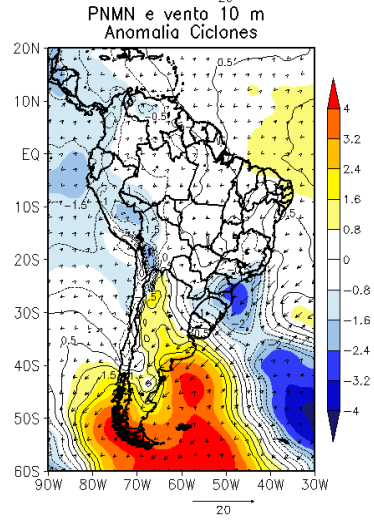

b)

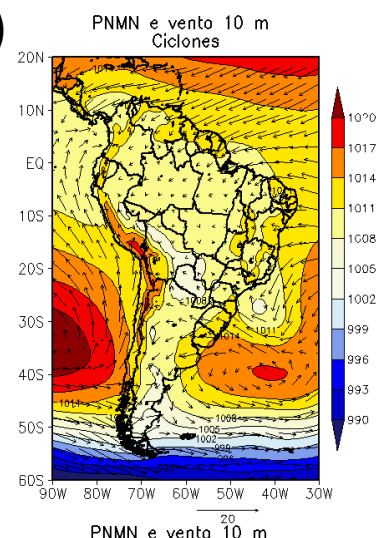

e)

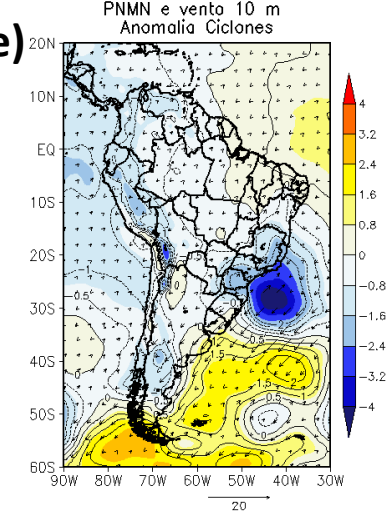

c)

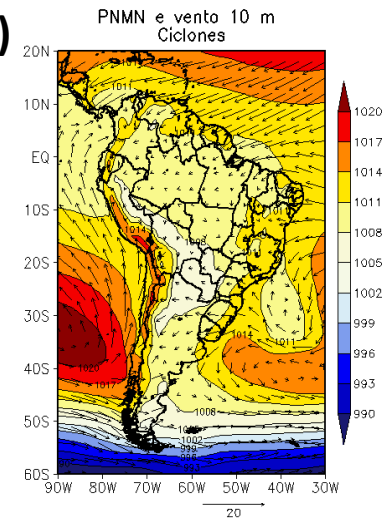

f)

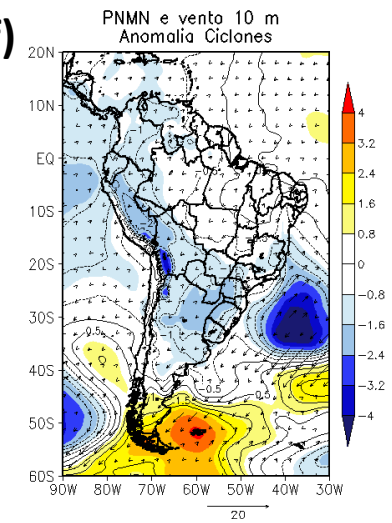

Figura 4 - Campos de pressão ao nível médio do mar $(\mathrm{hPa})$ e vetores do vento a 10 metros de altura $\left.\left.\left.\left(\mathrm{m} \mathrm{s}^{-1}\right): \mathrm{a}\right), \mathrm{b}\right), \mathrm{c}\right)$ composição dos eventos de ciclones, um dia anterior do aparecimento, no dia da gênese e um dia posterior ao aparecimento, no período de 
dezembro a fevereiro entre 2006 a 2017, respectivamente; d), e), f) diferença entre a composição dos casos de ciclones e a média dos eventos de ZCAS (anomalia) no período de dezembro a fevereiro entre 2006 a 2017.

Na Figura 5 d-f é mostrado que há mais umidade no ramo oceânico da ZCAS em eventos com ciclones. Portanto, os ciclones são importantes para os eventos de ZCAS a fim de organizar o transporte de umidade, como ressalta a Figura 6. Um fato interessante é que à medida que o ciclone se afasta da costa, a região de máxima umidade no continente migra do sul de São Paulo para o norte de Minas Gerais, como mostram as figuras da umidade especifica e precipitação (Figuras 6 e 7).

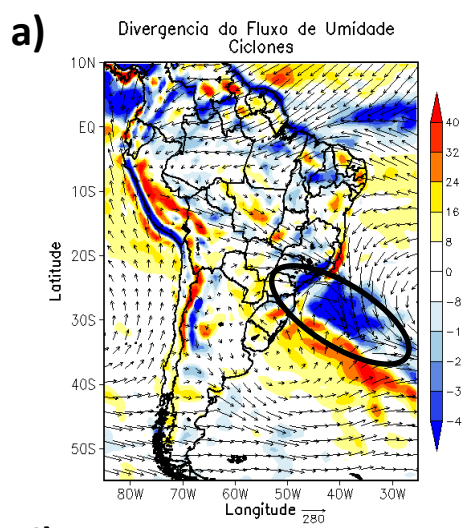

d) Divergencia do Fluxo de Umidade

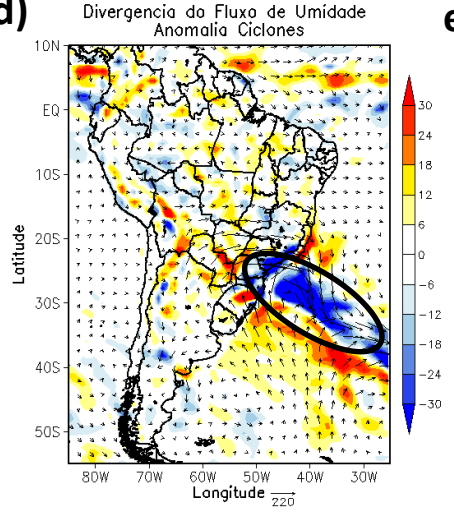

b)

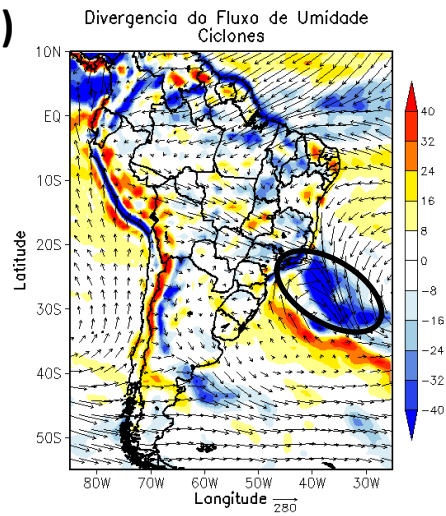

e)

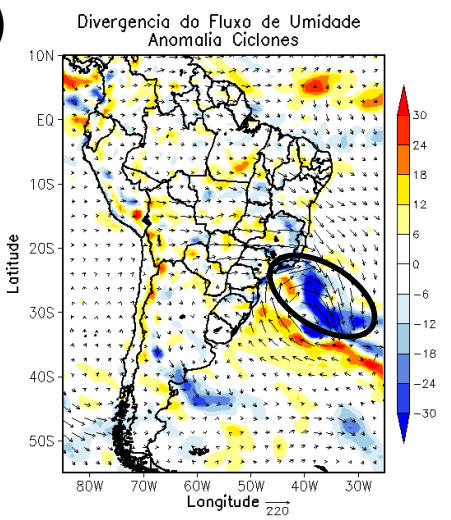

c)

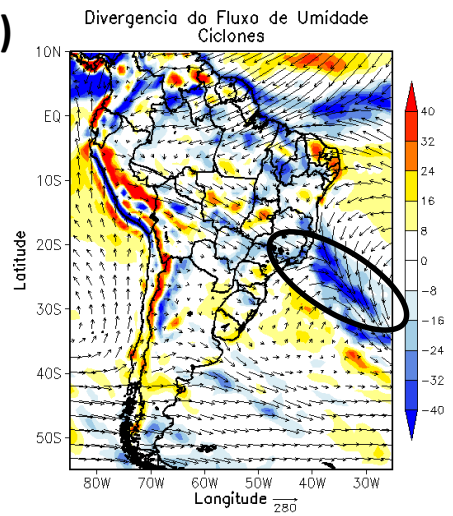

f)

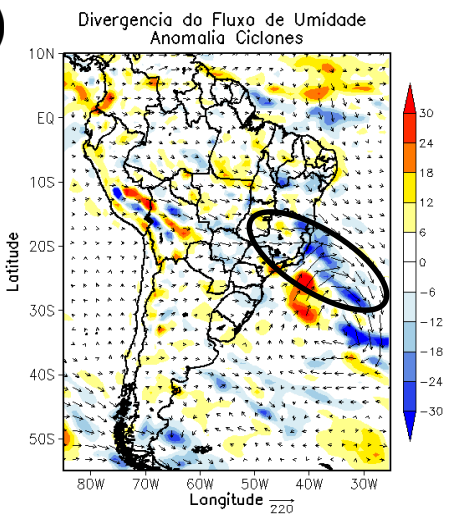

Figura 5 - Campo de divergência do fluxo de umidade integrado na vertical $\left(\mathrm{kg} \mathrm{m}^{-1} \mathrm{~s}^{-1}\right)$ : a), b), c) composição dos eventos de ciclones, um dia anterior do aparecimento, no dia da gênese e um dia posterior ao aparecimento, no período de dezembro a fevereiro entre 2006 a 2017, respectivamente; d), e), f) diferença entre a composição dos casos de ciclones e a média dos eventos de ZCAS (anomalia) no período de dezembro a fevereiro entre 2006 a 2017. 
a)

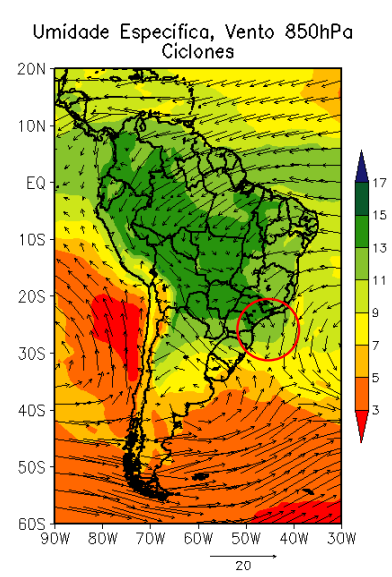

d)

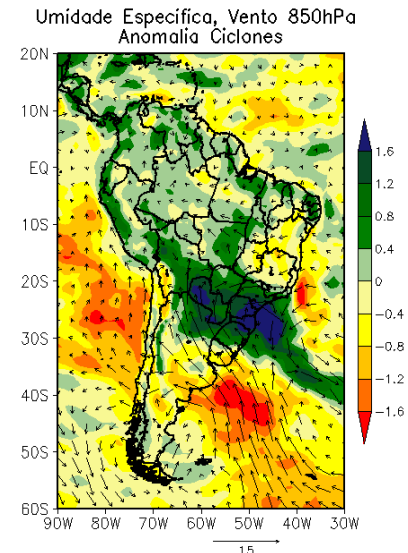

b)

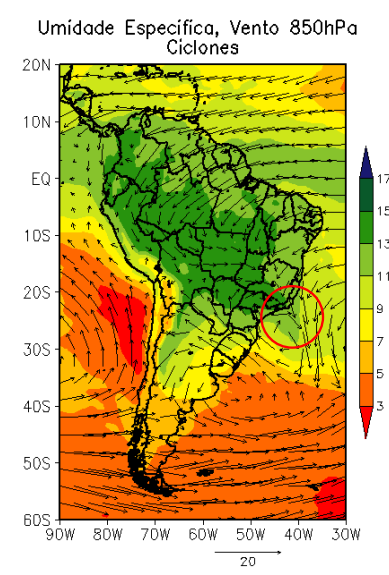

e)

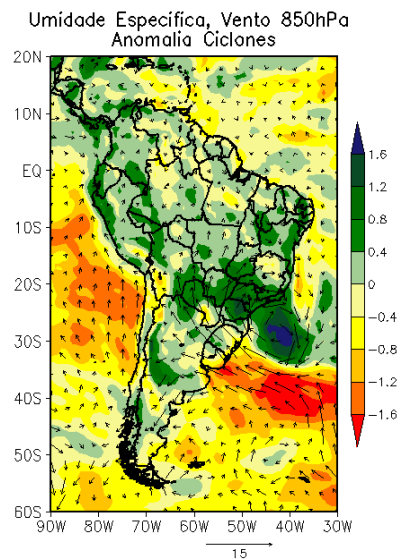

c)

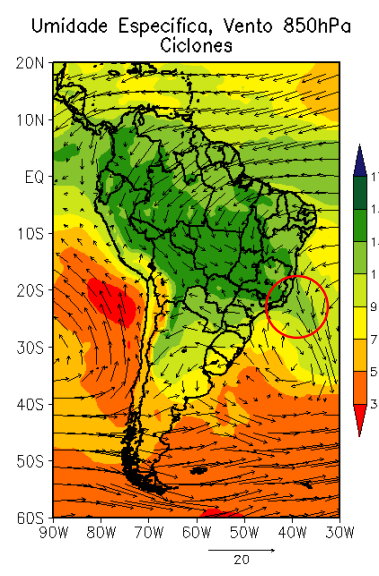

f)

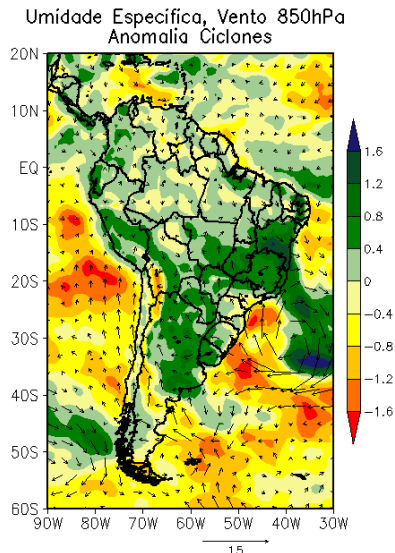

Figura 6 - Campo de umidade específica $\left(\mathrm{g} \mathrm{kg}^{-1}\right)$ e vetores do vento $\left(\mathrm{m} \mathrm{s}^{-1}\right)$ no nível de $850 \mathrm{hPa}:$ a), b), c) composição dos eventos de ciclones, um dia anterior do aparecimento, no dia da gênese e um dia posterior ao aparecimento, no período de dezembro a fevereiro entre 2006 a 2017, respectivamente; d), e), f) diferença entre a composição dos casos de ciclones e a média dos eventos de ZCAS (anomalia) no período de dezembro a fevereiro entre 2006 a 2017. 

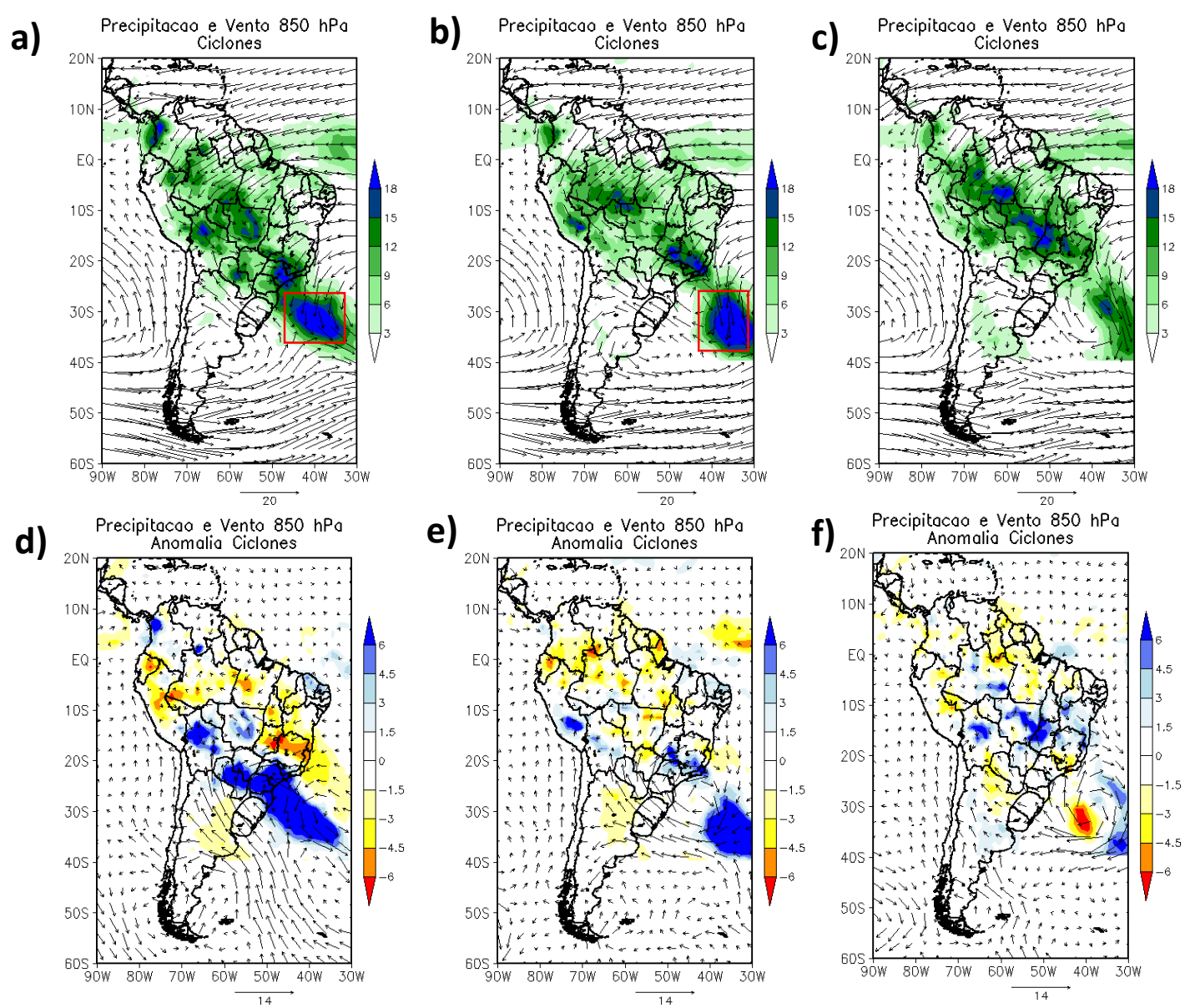

Figura 7 - Campo de Precipitação $\left(\mathrm{mm} \mathrm{dia}^{-1}\right)$ e vetores do vento $\left(\mathrm{m} \mathrm{s}^{-1}\right)$ no nível de 850 hPa: a), b), c) composição dos eventos de ciclones, um dia anterior do aparecimento, no dia da gênese e um dia posterior ao aparecimento, no período de dezembro a fevereiro entre 2006 a 2017, respectivamente; d), e), f) diferença entre a composição dos casos de ciclones e a média dos eventos de ZCAS (anomalia) no período de dezembro a fevereiro entre 2006 a 2017.

Por fim são mostradas as composições nos campos de divergência e linhas de corrente no nível de $300 \mathrm{hPa}$ (Figura 8) que indicam valores elevados de divergência na região de ocorrência dos ciclones estudados, o que dá suporte para a convergência em baixos níveis. No dia prévio à gênese, há um cavado com pequena amplitude sobre o Sul do Brasil com uma área de divergência estendendo-se de Santa Catarina para o oceano. Nessa região é que o ciclone se configura. Já no dia da gênese, o cavado está mais amplificado e o máximo de divergência aparece deslocado da costa, indicando a localização futura do ciclone. Esses valores elevados são melhores evidenciados nas figuras das gêneses dos ciclones (Figura 8b, e). 
a)

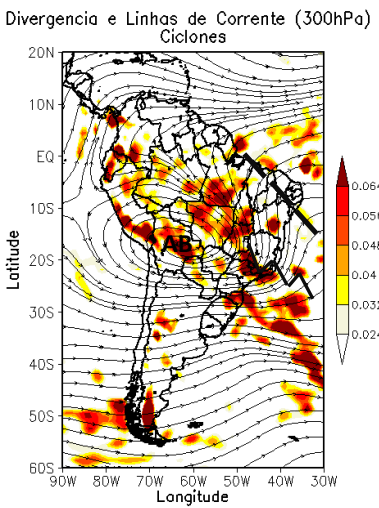

d)

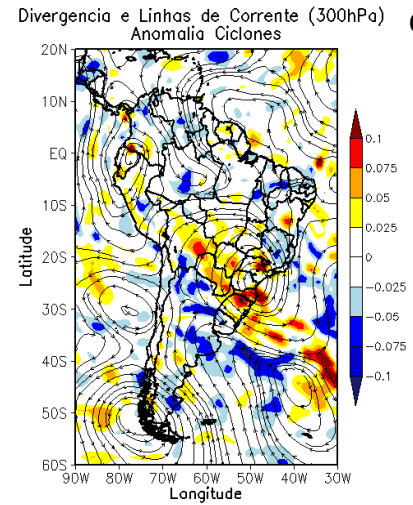

b)

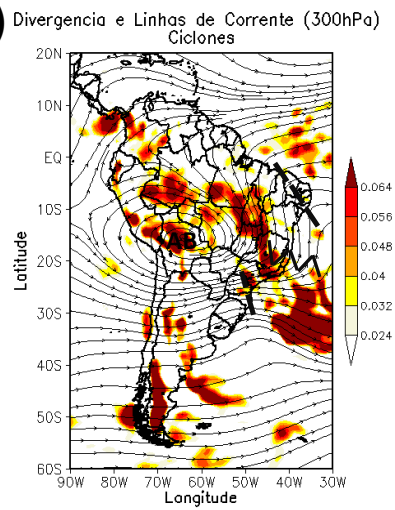

e)

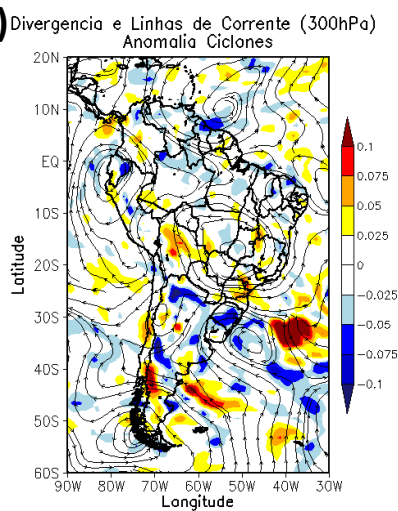

C) Divergencia e Linhas de Corrente (30ohPa)

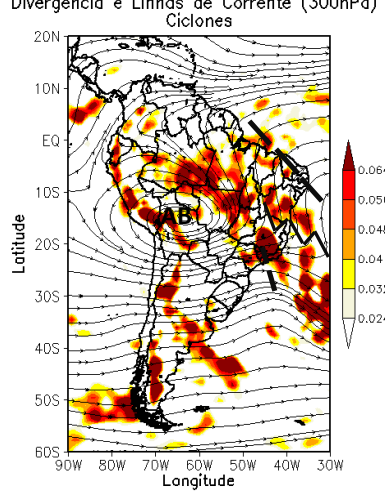

f) Divergencia e Linhas de Corrente $(300 \mathrm{hPa})$

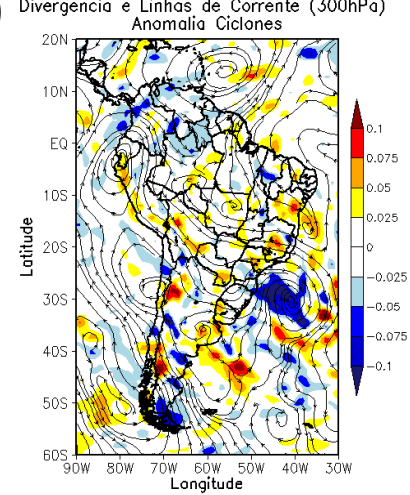

Figura 8 - Campo de divergência de massa $\left(1 \mathrm{~s}^{-1}\right)$ e linhas de corrente $\left(\mathrm{m} \mathrm{s}^{-1}\right)$ no nível de 300 hPa: a), b), c) composição dos eventos de ciclones, um dia anterior do aparecimento, no dia da gênese e um dia posterior ao aparecimento, no período de dezembro a fevereiro entre 2006 a 2017, respectivamente; d), e), f) diferença entre a composição dos casos de ciclones e a média dos eventos de ZCAS (anomalia) no período de dezembro a fevereiro entre 2006 a 2017.

Outra maneira de mostrar o transporte de umidade para a região dos ciclones é através da análise da trajetória das parcelas de ar obtida com o modelo Lagrangeano HYSPLIT. A Figura 9 destaca os 3 casos escolhidos para a gênese dos ciclones. A umidade presente na região dos ciclones se deve tanto ao transporte advindo do interior do continente, na região da ZCAS (Figura 9a), como também pelo transporte proveniente do oceano Atlântico, o qual está associado aos ventos localizados na borda oeste do ASAS (Figura 9b).

a)

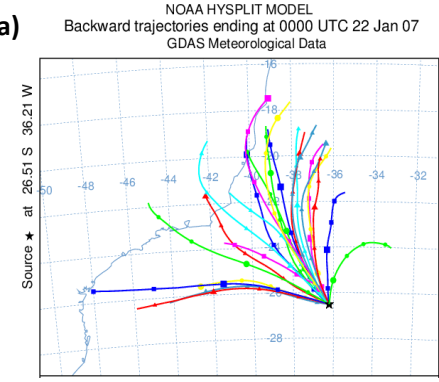

b)

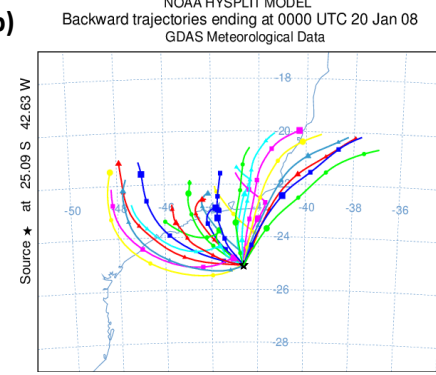

c)

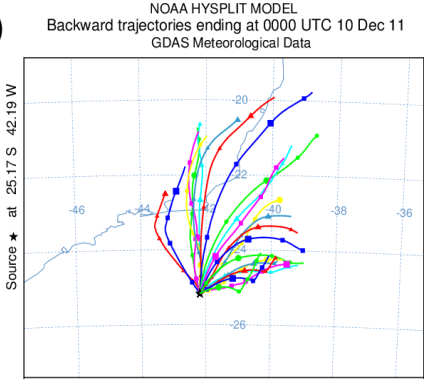

Figura 9 - Trajetória das parcelas de ar em direção às latitudes centrais dos ciclones no oceano Atlântico Sul, propostas pelo modelo HYSPLIT. 


\section{CONCLUSÕES}

Entre 2006 a 2017, foram registrados 114 casos de ZCAS. O mês com maior frequência desse evento é dezembro e o de menor frequência é abril. Em geral, os eventos de ZCAS possuem duração média de 5 dias. Considerando apenas o verão, foram identificados 63 casos de ZCAS.

Para a estação do verão, foram analisadas as características dos eventos de ZCAS em relação à climatologia dessa estação do ano. As características mais marcantes durante os eventos de ZCAS são: (1) a presença de um padrão do tipo gangorra entre o Sudeste e o Sul do Brasil, nas variáveis que indicam umidade na atmosfera, em que há anomalias positivas no Sudeste do Brasil e negativas no Sul, (2) a circulação em $850 \mathrm{hPa}$ mostra o JBN dirigido para o Sudeste do Brasil e a convergência desse escoamento com os ventos do setor oeste do ASAS que vão em direção ao continente, (3) presença de um cavado em níveis médios e altos da atmosfera entre o Sul do Brasil e oceano Atlântico dando suporte para a divergência em altos níveis e ocorrência de movimentos ascendentes na região do ramo oceânico da ZCAS e (4) nos episódios de ZCAS, em altos níveis, a crista sobre o Sudeste do Brasil é melhor configurada do que na climatologia do verão. No interior do continente (Amazônia e parte da região Centro-Oeste do Brasil) praticamente não ocorrem diferenças entre as composições da ZCAS e a climatologia do verão. Todas as características descritas são sintetizadas no modelo conceitual mostrado na Figura 10.

Cerca de $30 \%$ dos eventos de ZCAS estão associados com ciclones no oceano Atlântico Sul. Esses ciclones têm como fonte de umidade, o interior do continente, cuja umidade é transportada pelo JBN, e o oceano Atlântico tropical, em que a umidade é transportada pelos ventos do setor oeste do ASAS. Portanto, os ciclones são importantes para a manutenção da ZCAS.

Esse estudo fornece um "retrato" da ZCAS em diferentes variáveis atmosféricas servindo como subsídio para auxiliar as práticas de previsão do tempo. 
a) CLIMATOLOGIA

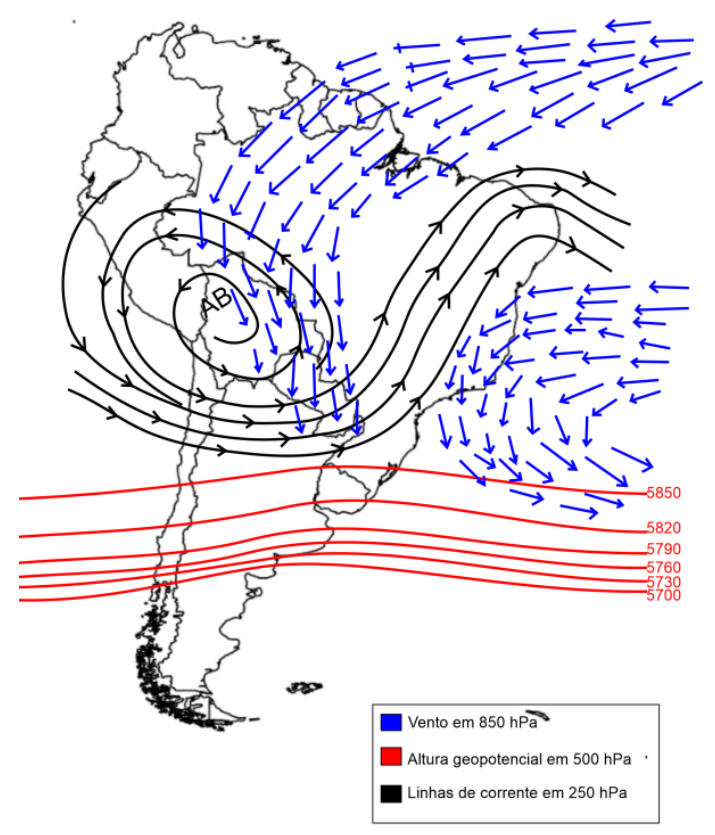

b) EVENTOS DE ZCAS

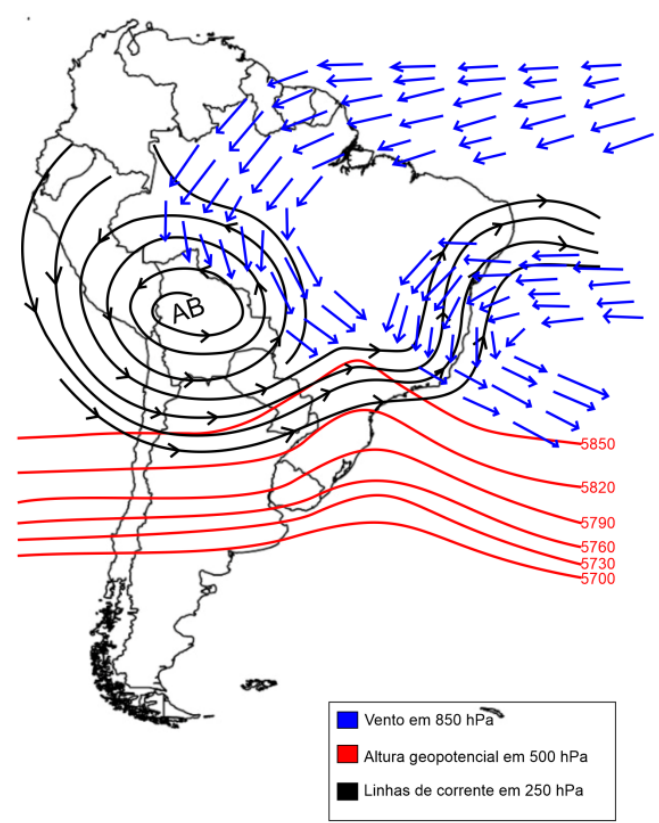

Figura 10 - Circulação atmosférica e baixos, médios, altos níveis na a) climatologia de verão e b) em eventos de ZCAS.

\section{AGRADECIMENTOS}

Agradecemos ao Centro de Previsão de Tempo e Estudos Climáticos (CPTEC) do Instituto Nacional de Pesquisas Espaciais (INPE), European Centre for Medium-Range Weather Forecasts (ECMWF), Global Precipitation Climatology Project (GPCP) e ao Instituto Nacional de Meteorologia (INMET) pelo fornecimento dos dados utilizados no presente estudo, e a Fundação de Amparo à Pesquisa do Estado de Minas Gerais (FAPEMIG), ao Conselho Nacional de Desenvolvimento Científico e Tecnológico (CNPq) pelo auxílio financeiro e a Renan Sales Rodrigues.

\section{REFERÊNCIAS}

ADLER, R. F.; HUFFMAN, G. J.; CHANG, A.; FERRARO, R. ;XIE, P.; JANOWIAK, J.; RUDOLF, B.; SCHNEIDER, U.; CURTIS, S.; BOLVIN, D.; GRUBER, A.; SUSSKIND, J.; ARKIN, P.; NELKIN, E. The version-2 global precipitation climatology project (GPCP) monthly precipitation analysis (1979-present), J. Hydrometeor., 4, 1147-1167, 2003.

AMBRIZZI, T., FERRAZ, S. E. T. An objective criterion for determining the South Atlantic Convergence Zone. Frontiers in Environmental Science, v.3, article 23, 2015. 
CAMPETELLA, C. M.; VERA, C. S. The influence of the Andes mountains on the South American low-level flow. Geophysical Research Letters, v. 29, 2002.

CARVALHO, L. M. V; JONES, C.; LIEBMANN, B. The South Atlantic convergence zone: Intensity, form, persistence, and relationships with intraseasonal to interannual activity and extreme rainfall. Journal of Climate, v. 17, p. 88-108, 2004.

DEE, D. P.; UPPALA, S. M.; SIMMONS, A. J.; BERRISFORD, P.; POLI, P.; KOBAYASHI, S.; ANDRAE, U.; BALMASEDA, M. A.; BALSAMO, G.;BAUER, P.; BECHTOLD, P.; BELJAARS, A.; VAN DE BERG, L.; BIDLOT, J.; BORMANN, N.; DELSOL, C.; DRAGANI, R.; FUENTES, M.; GEER, A. J.; HAIMBERGER, L.; HEALY, S. B.; HERSBACH, H.; HÓLM, E. V.; ISAKSEN,L.; KALLBERG, P.; KÖHLER, M.; MATRICARDI, M.; MCNALLY, A.P.; MONGE-SANZ, B. M.; MORCRETTE， J.J.; PARK, B. K.; PEUBEY, C.;DE ROSNAY, P.; TAVOLATO, C.; THÉPAUT, J.N.; AND VITART, $F$. The ERA-Interim reanalysis: configuration and performance of the data assimilation system, Q. J. Roy. Meteorol. Soc., 137, 553-597, 2011.

DRUMOND, A.; NIETO, R.; GIMENO, L.; AMBRIZZI, T. A Lagrangian identification of major sources of moisture over Central Brazil and La Plata Basin. Journal of Geophysical Research, v. 113, 2008.

DURÁN-QUESADA, A.M.; REBOITA, M. S.; GIMENO, L. Precipitation in tropical America and the associated sources of moisture: a short review. Hydrological Sciences Journal, v. 57, p. 1-13, 2012.

ESCOBAR, G.C.J.; COSTA, I.C. Situações meteorológicas associadas a episódios da Zona de Convergência do Atlântico Sul (ZCAS). In: IX CONGRESO ARGENTINO DE METEOROLOGIA, 2005, Buenos Aires. Anais do IX CONGRESO ARGENTINO DE METEOROLOGIA.

ESCOBAR, G.C.J. CLIMATOLOGIA SINÓTICA ASSOCIADA COM EPISÓDIOS DE ZONA DE CONVERGÊNCIA DO ATLÂNTICO SUL (ZCAS). In: XX CONGRESSO BRASILEIRO DE METEOROLOGIA, 2018, Maceió. Anais do XX CONGRESSO BRASILEIRO DE METEOROLOGIA.

ESCOBAR, G.C.J, MATOSO, V. ZONA DE CONVERGÊNCIA DO ATLÂNTICO SUL (ZCAS): DEFINIÇÃO PRÁTICA SEGUNDO UMA VISÃO OPERACIONAL. In: $X X$ CONGRESSO BRASILEIRO DE METEOROLOGIA, 2018, Maceió. Anais do XX CONGRESSO BRASILEIRO DE METEOROLOGIA.

GOZZO, L. F.; ROCHA, R. P.; GIMENO L.; DRUMOND, A. Climatology and numerical case study of moisture sources associated with subtropical cyclogenesis over the southwestern Atlantic Ocean. J. Geophys Res-Atmos. v. 122 , p.5636-5653, 2017.

HERDIES, D. L.; SILVA, A.; SILVA DIAS, M. A. F.; FERREIRA, R. N. Moisture budget of the bimodal pattern of the summer circulation over South America. Journal of Geophysical Research, v. 107, n. D20, 8075, 2002.

KOUSKY, V. E.; GAN, M. A. Upper tropospheric cyclonic vortices in the subtropical South Atlantic. Tellus, v. 33, p. 538-551, 1981.

KOUSKY, V. E.; ELIAS, M. Meteorologia Sinótica: Parte I. INPE: São José dos Campos, 1982. 105 p. (INPE-2605-MD/021). 
KOUSKY, V. E. Pentad outgoing longwave radiation climatology for the South American sector. Revista Brasileira de Meteorologia, n. 3, p. 217-231, 1988.

LENTERS, J.D.; K.H. COOK. Summertime precipitation variability over South America: Role of the large-scale circulation. Monthly Weather Review. n.127, p. 409-431, 1997.

MARENGO, J. A.; LIEBMANN, B.; KOUSKY, V.; FILIZOLA, N. WAINER, I. On the onset and end of the rainy season in the Brazilian Amazon Basin. Journal of Climate, v.14, p. 833-853, 2001.

MARENGO, J. A.; LIEBMANN, B.; GRIMM, A. M.; MISRA, V. SILVA DIAS, P. L.; CALVALCANTI, I. F. A.; CARVALHO, L. M. V.; BERBERY, E. H.; AMBRIZZI, T.; VERA, C. S.; SAULO, A. C.; NOGUES-PAEGLE, J.; ZIPSER, E.; SETH, A. ; ALVES, L. M. Review recente developments on the South American monsoon system. International jornal of Climatology, v. 32, n. 1, p. 1-21, 2012.

NOGUÉS-PEAGLE, J.; MO, K. C. Alternating wet and dry conditions over South America during summer. Monthly Weather Review, vol. 125, p. 279-291, 1997.

NOGUÉS PEAGLE, J.; MECHOSO, C. R.; e coautores. Progress in Pan America CLIVAR Research: Understanding the South American Monsoon. Meteorologica, v. 27, p. 3-30, 2002.

QUADRO, M.F.L. Estudo de Vórtices Ciclônicos de Mesoescala associados à Zona de Convergência do Atlântico Sul. 2012. 141 f. Tese (Doutorado em Meteorologia) - Instituto de Astronomia, Geofísica e Ciências Atmosféricas, Universidade de São Paulo, São Paulo.

RAMAGE, C. S. Monsoon Meteorology. Academic Press, 279pp, 1971.

REBOITA, M. S.; GAN, M. A.; ROCHA, R. P.; AMBRIZZI, T. Regimes de precipitação na América do Sul: uma revisão bibliográfica. Revista Brasileira de Meteorologia, v. 25, n. 2, p. 185-204, 2010.

REBOITA, M. S.; MARIETTO, D.M.G.; SOUZA, A.; BARBOSA, M. Caracterização Atmosférica quando da ocorrência de eventos extremos de chuva na região Sul de Minas Gerais. Revista Brasileira de Climatologia. [S.I.], v. 21, ago. 2017.

REBOITA, M. S.; CAMPOS, B.; SANTOS, T.; A.; CARVALHO, V. S. B. Análise sinótica e numérica de um VCAN no Nordeste do Brasil. Revista Brasileira de Geografia Física, v. 10, p. 41-59, 2017.

REBOITA, M.S., ROCHA, R.P., OLIVEIRA, D.M. Key Features and Adverse Weather of the Named Subtropical Cyclones over the Southwestern South Atlantic Ocean. Atmosphere - aguardando publicação, 2018.

REBOITA, M.S.; AMBRIZZI, T. SILVA, B.A.; PINHEIRO, R.F.; ROCHA, R.P. The South Atlantic Subtropical Anticyclone: Present Climate and Future Projections. Frontiers in Earth Science. v. 7, n. 8, p. 1-15, 2019.

SANTOS, D.F.; REBOITA, M.S. Jatos de baixos níveis a leste dos andes: comparação entre duas reanálises. Revista Brasileira de Climatologia, [S.I.], v. 22, maio 2018.

SELUCHI, M. E., E S. C. CHOU. Synoptic patterns associated with landslide events in the Serra do Mar, Brazil. Theoretical and Applied Climatology, 98, 6777, 2009. 
STEIN, A.F.; DRAXLER, R.R.; ROLPH, G.D.; STUNDER B.J.; COHEN, M.D.; NGAN, F. NOAA's HYSPLIT Atmospheric Transport and Dispersion Modeling System. American Meteorological Society, v.96, p.2059-2077, 2015.

SUTCLIFFE, R.C. A Contribution of the Problem of Development. Quarterly Journal of the Royal Meteorological Society, v. 73, p.370-383, 1947

ZHOU, J.; LAU, K. M. Does a Monson Climate Exist Over South America. Journal of Climate, v.11, n.5, p.1020-1040, 1998. 